\title{
Trigonocephaly-broad thumbs syndrome
}

INSERM

\section{Source}

INSERM. (1999). Orphanet: an online rare disease and orphan drug data base.

Trigonocephaly-broad thumbs syndrome. ORPHA:3365

Trigonocephaly-broad thumbs syndrome is characterized by neonatal trig onocephaly and multiple anomalies including craniosynostosis, shallow orbits, unusual nose, deviation of the terminal phalanges of fingers 1, 2, and 5, and broad toes with duplication of the terminal phalanx. It has been described in a mother and her son. It is transmitted as an autosomal dominant trait. 